\title{
Young people's knowledge of the UK criminal justice system and their human rights
}

\author{
Karen Barnes ${ }^{\dagger}$ and J. Clare Wilson ${ }^{\ddagger}$ \\ ${ }^{\dagger} \mathrm{KMPG}$, Learning and Development, Stoke Place, St Stephens Green, Dublin 2, Ireland \\ ${ }^{\ddagger}$ (Corresponding author) Department of Psychology, University of Portsmouth, King Henry \\ 1 Street, Portsmouth, PO1 2DY, UK. Email: clare.wilson@port.ac.uk
}

Received 23 February 2007; accepted 22 May 2007

Keywords: human rights, youth, UK criminal justice, incarceration

Karen Barnes is a forensic psychologist currently working in the Learning and Development Department for KPMG, Dublin, Ireland.

J. Clare Wilson is a chartered forensic psychologist currently working as a Reader in Forensic Psychology at the University of Portsmouth. offender groups. In conclusion, the current level of understanding and attitudes of young offenders about the criminal justice system and their human rights suggest that they may be limited in their capacity to make informed decisions regarding active participation.

\section{INTRODUCTION}

Under the United Nations Convention on the Rights of the Child (1990), Article 12, young defendants have the right to understand and participate in court proceedings. This sentiment is further reflected in Article 6 of the European Convention on Human Rights. To exercise these rights, the young offender must first understand that such rights exist and have some understanding of the criminal justice process. However, research has shown that most young offenders fall short of having a basic understanding of the UK criminal justice system and often have very negative attitudes towards it (Plotnikoff \& Woolfson, 2003). The present paper will explore whether those young offenders who are more experienced with the UK criminal justice system understand it better than those young offenders who are new to the system 
and young people who are better educated but have had no direct experience.

\section{Young people's understanding of the criminal justice system}

Research investigating children's and young people's knowledge of the criminal justice system has examined their knowledge of legal terminology (Flin, Stevenson, \& Davies, 1989; Peterson-Badali \& Abromovitch, 1992; Saywitz, Jaenicke, \& Comparo, 1990), conceptions of the legal system (Martin \& Cohn, 2004; Saywitz, 1988), and attitudes towards legal institutions and to the police (Hurst \& Frank, 2000; Mylonas \& Reckless, 1963). Usually this research has been conducted with potential child witnesses and emphasised the importance of children's knowledge and how it may play a contributing role to the child's performance as a witness in court (Flin et al.; PetersonBadali \& Abromovitch; Saywitz; Saywitz et al.).

Few studies have examined young offenders' knowledge of the criminal justice system (see Plotnikoff \& Woolfson, 2003). However, offender-relevant knowledge formed part of Peterson-Badali and Abromovitch's (1992) study involving court scenarios with children aged 9-17 years. They examined children's knowledge of lawyer-client confidentiality, and the meaning of a guilty/not guilty plea. However, only 2 per cent were able to define the plea of guilty or not guilty accurately; they did not comprehend the lawyer-client confidentiality agreement, and misunderstood the right to be presumed innocent until proven guilty. Thus, whilst knowledge may increase with age, children may misunderstand and misinterpret the basic concepts in the courts (Flin et al., 1989; Peterson-Badali \& Abromovitch). It remains to be seen if increased experience of the criminal justice system may also lead to a better understanding of the criminal justice system (eg Grisso, 1981).

\section{Attitudes toward the criminal justice system (CJS)}

Studies have investigated attitudes toward legal institutions (eg Clark \& Wenninger, 1964; Mylonas \& Reckless, 1963) and attitudes toward the police (eg Hurst \& Frank, 2000). For example, Mylonas and Reckless explored adult prisoners' attitudes toward the law and legal institutions. Results indicated that the offenders who had a higher morale had the most positive attitudes. Further, first-time incarcerated offenders had a more favourable attitude than those who had been incarcerated previously. Thus, the more times one returns to prison, the less favourable attitudes become (Mylonas \& Reckless).

Research has also investigated young peoples' attitudes toward legal institutions and found that those young people who experienced negative contacts with members of the legal agencies had a negative view of the law (Clark \& Wenninger, 1964; Griffiths \& Winfree, 1982; Rusinko, Johnson, \& Hornung, 1978). These findings may assist in explaining why offenders experienced with incarceration may have higher levels of negativity than those who are in prison for the first time.

Rogowski (2000) found that young offenders viewed the courts and the legal proceedings as a means of punishment as opposed to the implementation of justice and fairness. According to the young offenders, the solicitor 'was in it for the money' (p. 62). When asked about sentencing, the young offenders felt that it had little impact on reducing reoffending behaviour. These findings may seem understandable; however, there is evidence that the problem is more complex. Hazel, Hagell, and Brazier (2002) also examined young offenders' perceptions of their experiences in the criminal justice system. The offenders reported not understanding 
the court language and often misinterpreted the court proceedings. In addition to this, the defendants felt intimidated and isolated in the court room, with delays in the system leading to anxiety and frustration. Their frustration was increased when they felt they could not correct what the witnesses had said, and that they were not consulted when decisions were made about their future (Hazel et al.). Additionally, the events that occurred in the court room were often explained after the process had taken place. Participants often blamed the professionals for what happened to them and tended not to see their treatment as a result of legal events (Hazel et al.). These findings were similarly supported by Plotnikoff and Woolfson (2003). The defendants in this study reported that they were 'discouraged' from participating or speaking in court. Further, many did not possess the necessary communication skills to take an active role in court. There was a lack of support for the young defendants when they should have been encouraged to speak out, subsequently leading to increased stress (Plotnikoff \& Woolfson). Some did not actively partake in the hearing as they 'just wanted it to be over' (Plotnikoff \& Woolfson). Indeed, the stress caused by attending court was often too much for some defendants, who reported drinking or taking drugs to get through the hearing. Again, these researchers found that offenders were blaming the system for their current situation (Plotnikoff \& Woolfson).

Finally, research has explored children's feelings towards the police service. Hurst and Frank (2000) interviewed school children about their general attitudes towards the police force and also about their attitudes towards the police who worked in their area. Young people were said to display considerably less support for the police than previously found in adults (Hurst \& Frank).
Only 33 per cent of the children liked the police and under 40 per cent said that they were doing a good job. Furthermore, children living in urban areas were more negative than those living in the suburbs. Perhaps not surprisingly, Hazel et al. (2002) found that offenders were also negative about the police and felt unfairly discriminated against by them.

\section{Young people's knowledge of human rights}

The United Nations International Children's Emergency Fund (UNICEF) carried out a survey examining young people's views, concerns, hopes and dreams, known as 'Young Voices', which spread across 35 countries (UNICEF, 2001). This research included questions asking children about their human rights. 12 per cent said that they knew a lot about their rights; 42 per cent said they had some basic knowledge of their rights and 46 per cent said they knew little or none. Of those who reported knowledge of rights, 60 per cent said that they could not name any rights, while 20 per cent reported the right to freedom and dignity. Although the number of questions about human rights was limited, the results do indicate how uninformed young people are about their rights.

\section{The present study}

The present study examined young offenders' (those experienced and inexperienced with incarceration and therefore with court) understanding and attitudes towards their human rights and the criminal justice system. Their responses will be compared with a similar aged control group of school children and university students. This will allow some understanding of how much knowledge and attitude formation was experienced-based (the Offenders Experienced with Incarceration versus Offenders 
Inexperienced with Incarceration), or taught (the educated control group). As the majority of young offenders are likely to have truanted from school, they are unlikely to have been taught much about their rights and are also likely to have limited literacy skills. Thus, the inability to read or write may further limit their access to information and ultimately their comprehension of the criminal justice system and human rights. However, the present study only included those offenders who could read and write. Thus, the young offenders in the present study are more likely than the general population of young offenders to be able to access and understand written material.

The present study had five main hypotheses. First, it was predicted that knowledge of the criminal justice system (CJS) would be positively correlated with age for each of the three groups (Offenders Experienced with Incarceration, Offenders Inexperienced with Incarceration and Controls). Thus, the older you are, the more you are expected to know about the CJS and human rights. Second, it was predicted that there will be a significant positive relationship between experience with the CJS and knowledge (that is, the more experience one has with the CJS, the more one will know about it). Third, it was predicted that young offenders will have a significantly more negative attitude towards the CJS than the Controls. Fourth, it was predicted that there will be a significant negative relationship between attitude and knowledge of the CJS (that is, the more one knows, the less one will be positive about the CJS). Finally, it was predicted that there will be similar effects of attitudes and knowledge toward human rights as is predicted toward the CJS. However, it is likely that the participants will know significantly less about human rights than about the CJS.

\section{METHOD}

\section{Participants}

400 young people were sent questionnaires, 141 replied. The participants were all male aged 14-24 years. The Offenders Experienced with Incarceration group consisted of 56 incarcerated participants $(M=17.00$ years, $S D=2.40$ ) (Convictions: $M=4.34$, $S D=4.40)$. The Offenders Inexperienced with Incarceration group consisted of 25 incarcerated participants $(M=19.00$ years, $S D=2.20$ ). Examples of the participants' offences include: attempted murder, bomb hoax, drug dealing, grievous bodily harm, theft and assault. The Control group of students consisted of 60 participants $(M=18.00$ years, $S D=1.90)$. The Offenders Experienced with Incarceration and Offenders Inexperienced with Incarceration were selected from three prisons in the United Kingdom (UK). The Controls were students selected from a secondary school in the UK and University of Kent. All participation was voluntary.

\section{Materials}

The questionnaire was devised for the present study. The questionnaire was divided into three main sections: Section A, the courts and the police; Section B, the court personnel; and Section $\mathrm{C}$, human rights that related to the criminal justice process. In each section there were 20 statements measuring the participant's knowledge (eg police are not allowed to give me any food when I am being questioned) and 20 statements measuring their attitude (eg the judge is always out to get me), with 120 statements in total. Ideas were gathered in part from previous research (Flin et al., 1989; Saywitz, 1988; Saywitz et al., 1990) but mainly from statements taken from interviews in a pilot study which asked young offenders about their knowledge and attitudes towards the criminal justice system and their human rights (due to the use of 
interview statements in the questionnaire there were more negatively phrased statements than positively phrased statements). The statements were rated on a 5-point Likert scale, from strongly disagree to strongly agree. The participants were asked to circle the number that matched how much they agreed or disagreed with the statement.

Cronbach's alpha was computed to analyse the reliability of the three sections, all were within an acceptable reliability range; police and the courts had an alpha of 0.76 ; the court personnel had an alpha of 0.82 and the human rights section had an alpha of 0.87 . The attitudes in Section A and B were summed for a total attitudes towards CJS score and the knowledge scores for Section A and B were summed for a total knowledge towards CJS score.

\section{Procedure}

The questionnaires took 25 minutes to complete. Each participant was provided with a copy of the questionnaire, information sheet and consent form. All participants were informed that they were free to withdraw at any time. Questionnaires completed by incarcerated offenders were administered by the prison psychologist. The prison psychologist chose offenders who could read and write. Participants were informed that if anything was unclear they might ask the prison psychologist for assistance. The teacher administered those questionnaires completed by school children. The questionnaires completed by the university students were administered via electronic mail.

\section{RESULTS}

\section{The criminal justice system}

First, when a Pearson product-moment correlation was conducted, a strong positive correlation was found between age and knowledge of the criminal justice system, $r(139)=0.40, p<0.01$.

Second, when a Pearson $r$ correlation was carried out, no significant relationship was found between experience in the criminal justice system and knowledge of the criminal justice system, $r(139)=0.140$, $p>0.05$.

Third, a one-way ANOVA was conducted to test if Offenders Experienced with Incarceration and Offenders Inexperienced with Incarceration were significantly different from the controls in their attitude towards the criminal justice system. There was a significant difference, $F(2,138)=22.52, p<0.001$. A follow-up Tukey HSD test was conducted to evaluate pairwise differences among the means. Offenders Experienced with Incarceration $(M=107.00, S D=18.50)$ were significantly more negative towards the criminal justice system than the Offenders Inexperienced with Incarceration $(M=136.00$, $S D=19.10), p<0.001$ and the Controls $(M=132.00, S D=27.10), p<0.001$. However, there was no significant difference between Offenders Inexperienced with Incarceration and the Controls.

Fourth, when a Pearson $r$ correlation was carried out, no relationship was found between attitudes towards the criminal justice system and knowledge of the criminal justice system, $r(139)=0.08, p>0.05$.

\section{Human Rights}

First, when a Pearson $r$ correlation was carried out, there was a significant positive correlation between attitudes towards human rights and knowledge of human rights, $r(139)=0.664, p<0.01$.

Second, a one-way ANOVA was conducted to test for group differences in their knowledge of human rights. A significant difference was found $F(2,138)=5.103$, $p<0.05$. A follow-up Tukey HSD test was conducted to evaluate pairwise differences among the means. Offenders Experienced 
with Incarceration $(M=67.80, S D=10.23)$ demonstrated significantly less knowledge of human rights than the Offenders Inexperienced with Incarceration $(M=75.12$, $S D=9.78), p<0.01$. However, the Controls $(M=71.83, S D=10.02)$ did not significantly differ from the Offenders Experienced with Incarceration and the Offenders Inexperienced with Incarceration.

Third and finally, a one-way ANOVA was conducted to investigate if Offenders Experienced with Incarceration and Offenders Inexperienced with Incarceration had more negative attitudes toward their human rights than the Controls. There was a significant difference between the groups, $F(2,138)=30.164, p<0.05$. A follow-up Tukey HSD test was conducted to evaluate pairwise differences among the means. Offenders Experienced with Incarceration $(M=60.64, S D=11.36)$ appeared to have significantly more negative attitudes towards their human rights than both Offenders Inexperienced with Incarceration $(M=78.24, S D=10.46), p<0.001$, and the Controls $(M=75.35, S D=12.55)$, $p<0.001$. However, there was no significant difference between the Controls and Offenders Inexperienced with Incarceration.

\section{DISCUSSION}

The present study found that knowledge of the criminal justice system was positively correlated with age overall and the young offenders did have a significantly more negative attitude towards the criminal justice system than the Controls (although this was only for those Offenders Experienced with Incarceration). However, there was not a significant relationship between experience with the criminal justice system and knowledge. Further, Offenders Experienced with Incarceration had the most negative attitude toward their human rights but their knowledge of human rights was significantly less than the Offenders Inexperienced with Incarceration (but no different from the Controls). Further, there was no relationship between attitudes and knowledge of the criminal justice system, but there was a positive relationship between attitudes and knowledge of human rights. Finally, it should be noted that as only literate offenders took part in the present study, it may be that illiterate offenders may know less.

\section{Criminal justice system}

First, knowledge was significantly positively correlated with age, supporting previous empirical research (Saywitz, 1988; Saywitz et al., 1990). The older participants knew more than the younger participants. Informal education may play a significant role in improving their understanding (such as television viewing or discussions with others). Future research might examine the role of legal education in schools and young offender institutions to improve young people's knowledge. However, a better education is not resulting from experience as there was no relationship between experience and knowledge. This appears counterintuitive as usually the more one does a task, the more one knows about the task. However, this supports Grisso's (1981) finding that more experience with the criminal justice system did not lead to an increase in knowledge. This may be because few young offenders are being aided in their understanding of the process, and once they have been through the process once, little further assistance is given in the expectation that they now should 'know it all'.

Second, Offenders Experienced with Incarceration differed significantly from the Offenders Inexperienced with Incarceration and Controls in their attitude towards the criminal justice process. The more contact with the system the more negative the 
attitudes became (Clark \& Wenninger, 1964; Griffiths \& Winfree, 1982; Hurst \& Frank, 2000; Rusinko et al., 1978). This again may be because Offenders Experienced with Incarceration are given less support (and yet may still not know what is going on) and thus become more negative (Plotnikoff \& Woolfson, 2003).

Finally, knowledge of the criminal justice system was unrelated to attitudes. Although this contradicts previous research (Rogowski, 2000), in the present study, experience (positive or negative) of the criminal justice system was a better predictor of attitudes than knowledge per se (which was extremely low).

\section{Human rights}

First, most young offenders in the present study demonstrated very little understanding of their human rights. Interestingly, Offenders Inexperienced with Incarceration were most aware of their human rights, scoring significantly higher than the Offenders Experienced with Incarceration and Controls (but all scores were low). This indicates that even if offenders had attended school and/or university (as was available to the Controls), this would not necessarily have enhance their understanding of their human rights. The UN Convention on the Rights of the Child (1990) states that the government is responsible for informing and educating children about their human rights. It appears that it has yet to do so.

Second, Offenders Experienced with Incarceration had significantly more negative attitudes about their human rights than the Controls and Offenders Inexperienced with Incarceration (these two groups did not differ). These results are similar to the attitudes towards the criminal justice system. This negativity towards human rights may be explained, in part, by the Offenders Experienced with Incarceration disillusionment and frustration with not knowing about their rights. There was also a significant positive relationship between participants' attitudes and their knowledge of human rights. Again, Offenders Experienced with Incarceration who had a poorer comprehension of their human rights also had more negative attitudes.

Finally, the participants were asked 'What is the most important Human Right do you think?'. However, as most responded that they did not know any, this question could not be further analysed (those few that were able to respond reported freedom of speech as being the most important). This further suggests a very low level of knowledge.

Future research may expand on the present study by examining where offenders are getting their information from and finding ways and methods to improve their education on these matters. For example, participants may be getting their information from legal programmes on television. According to previous research this does not affect the participants' level of knowledge of the criminal justice system (Gerbner, Gross, Signorielli, Morgan, \& Jackson-Beek, 1979; Saywitz, 1988). However, these studies were carried out almost 15 years ago, legal programmes are currently more widespread and popular and this could affect the responses to the questions about the criminal justice system.

\section{CONCLUSIONS}

The present research provided an insight into what young people know and their attitudes towards the criminal justice system. More specifically, the present study found remarkable differences between Offenders Experienced with Incarceration, Offenders Inexperienced with Incarceration and Controls, in both their knowledge and attitudes. It illustrates how young offenders' interest gradually decreases as they are continually convicted. Interestingly, Offenders Experienced with Incarceration do not know significantly more 
about the court process than Offenders Inexperienced with Incarceration. A large number of the offenders appear to have a general negative attitude towards the courts, the court personnel and their human rights. Those who work with young offenders may find it useful to consider these differences and the consequences of negative attitudes and lack of understanding. Finally, young people's lack of appropriate understanding of the criminal justice system and their human rights is a deep concern as this suggests that they may be unable to exercise their rights under the UN Convention on the Rights of the Child (1990).

\section{References}

Clark, J. P., \& Wenninger, E. P. (1964). The Attitude of Juveniles Toward Legal Institution. Journal of Crime, Law, Criminology and Police Science, 55, 482-489.

Flin, R. H., Stevenson, Y., \& Davies, G. (1989). Children's knowledge of the legal proceedings. British Journal of Psychology, 80, 285-297.

Gerbner, G., Gross, L., Signorielli, N., Morgan, M., \& Jackson-Beek, M. (1979). The demonstration of power: Violence profile No. 10. Journal of Communication, 48, 177-196.

Griffiths, C. T., \& Winfree, L. T. (1982). Attitudes toward the police: a comparison of Canadian and American adolescents. International Journal of Comparative and Applied Criminal Justice, 2, 127-141.

Grisso, T. (1981). Juvenile's Waiver of Rights: Legal and Psychological Competence. New York: Plenum Press.

Hazel, N., Hagell, A., \& Brazier, L. (2002). Young offenders' perceptions of their experiences in the Criminal Justice System. Unpublished paper. London, UK: Policy Research Bureau.

Hurst, Y. G., \& Frank, J. (2000). How kids view cops: The nature of juvenile attitudes towards the police. Journal of Criminal Justice, 28, 189-202.
Martin, T. A., \& Cohn, E. S. (2004). Attitudes towards the criminal legal system: Scale development and predictions. Psychology, Crime \& Law, 10, 367-391.

Mylonas, A. D., \& Reckless, W. C. (1963). Prisoners' Attitudes toward law and legal institutions. Journal of Criminal Law, Criminology and Police Science, 54(4), 479-484.

Peterson-Badali, M., \& Abromovich, R. (1992). Children's knowledge of the legal system: Are they competent to instruct legal counsel? Canadian Journal of Criminology, 34(4), 139-160.

Plotnikoff, J., \& Woolfson, R. (2003). Young Defendants Pack: Scoping Study for the Youth Justice Board. London: Home Office.

Rogowski, S. (2000). Young offenders: Their experiences of offending and the youth justice system. Youth and Policy, 70, 52-70.

Rusinko, W., Johnson, K., \& Hornung, C. (1978). The importance of police contact in the formulation of youths' attitudes toward the police. Journal of Criminal Justice, 6, 53-67.

Saywitz, K. (1988). Children's conceptions of the legal system: 'Court is a place to play basketball'. In S. J. Ceci, D. F. Ross, \& M. P. Toglia (Eds.), Perspectives on Children's Testimony (pp. 131-157). New York: Springer Verlag.

Saywitz, K., Jaenicke, C., \& Comparo, L. (1990). Children's knowledge of legal terminology. Law and Human Behaviour, 14(6), 523-535.

United Nations Convention of the Rights of the Child. (1990). Office of the High Commissioner for Human Rights. Article 12. Retrieved August 5, 2003, from http: //www.unhchr.ch/html/menu3/b/ k2crc.htm.

UNICEF. (2001, August). Young voices opinion survey of children and young people in Europe and Central Asia. UNICEF in partnership with the Organisation for Security and Cooperation in Europe, Office for Democratic Institutions and Human Rights (OSCE/ ODIHR). Geneva, Switzerland. 